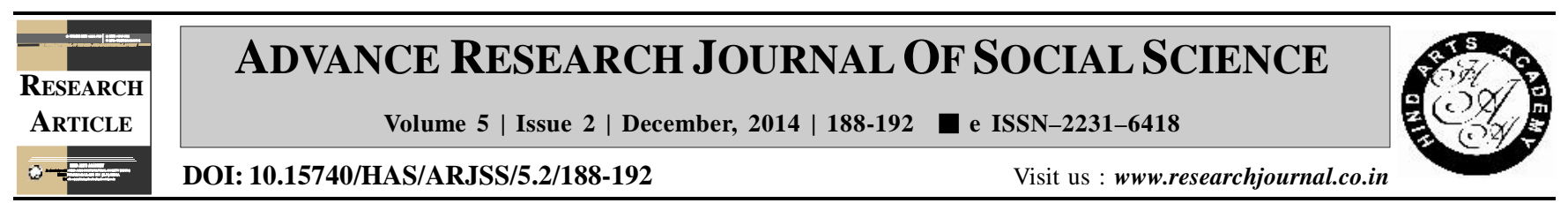

\title{
Entrepreneurship development programmes offered for women by KVK and RUDSETI
}

Yogita V. Masur*, Veena S. Jadhav and K. Sarojani ${ }^{1}$

Department of Family Resource Management, Rural Home Science College, University of Agricultural Sciences, DHARWAD (KARNATAKA) INDIA

${ }^{1}$ Krishi Vigyan Kendra (U.A.S.), DHARWAD (KARNATAKA) INDIA

(Email: yogitavm7@gmail.com)

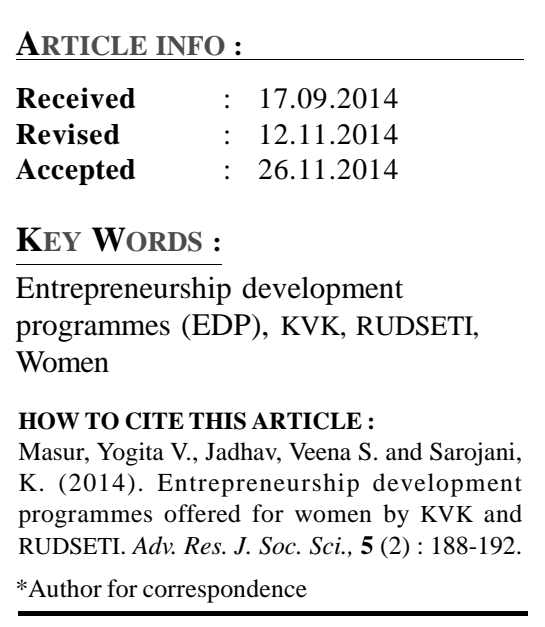

\begin{abstract}
Entrepreneurial Development programme can play an important role in influencing potential candidates to take advantage of new business opportunities and establish new business ventures. Women beneficiaries who had undergone Entrepreneurship Development Programmes between 2010-2013 from Dharwad and Hubli taluk were selected from the records of the respective training institutes. Highest number of women beneficiaries (224) had attended training on Integrated Farming System training which included Dairy, Poultry and Vermicomposting. The methodologies used in training included visits, Demonstration, Lecture session, Printed material and Group discussion in all the training programmes. Maximum number of women (131) had attended training on income generating activities which included potato chips making, roti making and paper bag making. 164 had attended training in Dairy. Total number of women beneficiaries in KVK were 342 and in RUDSETI 466 women beneficiaries had participated. both the institutes have provided follow up services and consultancy for all the women trainees.
\end{abstract}

